\title{
Effect of Cold Working on the Driving Force of the Crack Growth and Crack Growth Rate of Welded Joints under One Overload
}

\author{
Hongliang Yang $\mathbb{D},{ }^{1}$ He Xue $\mathbb{D}^{2},{ }^{2}$ Fuqiang Yang $\mathbb{D},{ }^{2}$ and Shuai Wang $\mathbb{D}^{2,3}$ \\ ${ }^{1}$ Center of Engineering Training, Xi'an University of Science and Technology, Xi'an 710054, China \\ ${ }^{2}$ School of Mechanical Engineering, Xi'an University of Science and Technology, Xi'an 710054, China \\ ${ }^{3}$ College of Engineering, Design and Physical Sciences, Brunel University London, Uxbridge UB8 3PH, UK \\ Correspondence should be addressed to Hongliang Yang; yanghongliang@xust.edu.cn and He Xue; xue_he@hotmail.com
}

Received 26 June 2020; Accepted 4 August 2020; Published 25 August 2020

Guest Editor: Guian Qian

Copyright (c) 2020 Hongliang Yang et al. This is an open access article distributed under the Creative Commons Attribution License, which permits unrestricted use, distribution, and reproduction in any medium, provided the original work is properly cited.

\begin{abstract}
To understand the effect of cold working of welding heat-affected zone on the driving force of the crack growth and crack growth rate of stress corrosion cracking (SCC) near the welding fusion line, the finite element simulation method was used to analyze the effect of cold working on the tensile stress of the crack tip at different locations near the fusion line. On this basis, the strain rate of the crack tip in the Ford-Andresen model is replaced by the creep rate of the crack tip, and the creep rate of the crack tip is used as driving force for the crack growth of SCC. The effect of the cold working level at the heat-affected zone on the driving force of the crack growth and crack growth rate of SCC are analyzed, and driving force of the crack growth and crack growth rate of SCC after one overload was compared.
\end{abstract}

\section{Introduction}

There are significant differences in mechanical properties of materials on the two sides of the fusion line of welded joints in nuclear power plants. The material composition and organization of the weld area after welding are extremely complex. At the same time, in the process of welding cooling, due to rapid decrease in the temperature of the weld zone, which causes cold shrinkage, it will have a tensile effect on materials in the heat-affected area, and the materials in the heat-affected area will have plastic deformation in different levels under the tensile effect, leading to different levels of cold working in the heat-affected zone $[1,2]$. Changes of mechanical properties in the heat-affected zone will affect distribution of stress and strain fields at the crack tip in different areas of welded joints, which can affect the driving force of the crack growth and crack growth rate. The SCC crack of welded joints in nuclear power plants is mainly in the weld and heat-affected zone near the fusion line [3]. In the service of material, the phenomenon that load suddenly increases in a short time and exceeds yield stress of the material and then, falls back to normal load is called one overload. One overload will occur due to a sudden increase of load when nuclear power pipelines and pressure vessels in service, for example, sudden increase of load caused by earthquake. Although duration of the one overload process is short, one overload also occurs occasionally in nuclear power plants. One overload will cause mechanical parameters of the microzone at the crack tip of SCC to change, and hardening of the crack tip will occur. One overload will cause mechanical parameters of the microregion at the SCC crack tip to change, and hardening of the crack tip will occur. SCC experiments have found that when loading amplitude changes suddenly or experiment is interrupted and restarted, the SCC crack growth is different $[4,5]$. Therefore, it is of practical engineering significance to study cold working on the SCC driving force of the crack growth and crack growth rate of welded joints in nuclear power plants under one overload.

\section{Theory of EAC Driving Force}

Ford and Andresen put forward the theory of slip dissolution/film fracture, and on the basis, the Ford-Andresen 
model [6] was proposed to predict the crack growth rate of SCC, which is also widely accepted and applied in the prediction model of SCC crack growth in a nuclear power high temperature water environment. The SCC crack growth rate $d a / d t$ can be expressed by

$$
\frac{d a}{d t}=\frac{M}{\rho \cdot z \cdot F} \cdot \frac{i_{0}}{1-m}\left[\left(\frac{t_{0} \cdot \dot{\varepsilon}_{\mathrm{ct}}}{\varepsilon_{f}}\right)^{m}-m \cdot\left(\left(\frac{t_{0} \cdot \dot{\varepsilon}_{\mathrm{ct}}}{\varepsilon_{f}}\right)\right)\right],
$$

where $M$ is the atomic weight, $\rho$ is the density, $z$ is the number of equivalents exchanged, $F$ is Faraday's constant, $m$ is the current attenuation curve exponent, $i_{0}$ is the oxidization current density, $t_{0}$ is the duration of constant, $\varepsilon_{f}$ is the fracture strain of the oxide film at the crack tip, and $\dot{\varepsilon}_{\mathrm{ct}}$ is the strain rate.

If $m \ll 1$ and $t_{\mathrm{f}} \gg t_{0}$, (1) can be simplified to

$$
\frac{d a}{d t}=\frac{M}{\rho \cdot z \cdot F} \cdot \frac{i_{0}}{1-m}\left(\frac{t_{0}}{\varepsilon_{f}}\right)^{m} \cdot\left(\dot{\varepsilon}_{\mathrm{ct}}\right)^{m} .
$$

From (2), it can be seen that the strain rate of the crack tip as a single mechanical influencing factor, the strain rate of the crack tip can be regarded as driving force of crack growth, the strain rate of crack tip is large, the driving force of crack growth is large, and the crack growth rate is also large.

SCC crack growth behavior can be regarded as a slow process of oxide film rupture and regeneration under the interaction of mechanics, materials, and corrosive environment at the crack tip. This process is consistent with the creep process. At the same time, the stress at the crack tip is constant for a long period of time, which meets the creep condition of metal. Studies have shown that creep has an important effect on the grain boundary slip at the crack tip. It can be considered that, during crack growth of SCC, rupture of the oxide film is due to grain boundary slippage caused by creep exceeding the rupture strength of the oxide film. Therefore, the creep rate of the crack tip instead of the strain rate of the crack tip is used as the driving force for crack growth:

$$
\dot{\varepsilon}_{c r}=\dot{\varepsilon}_{c t} .
$$

Nuclear power structural materials work at high temperature and high pressure, the microregion of the crack tip is a high stress area, and the creep rate usually changes exponentially with stress. Therefore, the creep rate of the crack tip is described by the Norton model which is exponential to the stress, as shown in the following equation:

$$
\dot{\varepsilon}_{c r}=A \sigma^{R}
$$

where $\dot{\varepsilon}_{c r}$ is the creep rate at the crack tip, $\sigma$ is the stress, $R$ is the creep stress exponent of material, $A$ is the Norton constant of material, $R=3.98$, and $A=1.153 \times 10^{-15} \mathrm{MPa}^{-1} \cdot \mathrm{h}^{-1}$.

According to the Ford-Andresen model, the quantitative prediction model of the SCC crack growth rate can be expressed as

$$
\dot{a}=k_{a}=\frac{M}{\rho \cdot z \cdot F} \cdot \frac{i_{0}}{1-m}\left(\frac{t_{0}}{\varepsilon_{f}}\right)^{m} \cdot\left(A \sigma^{R}\right)^{m} .
$$

$\kappa_{\mathrm{a}}$ can be calculated by the values of standard electrochemical and material parameters [7], and $\kappa_{\mathrm{a}}=8.643 \times 10^{-4}$.

\section{Finite Element Modeling}

3.1. Geometric Model. Taking welded joints in nuclear power plants as the research object, in finite element analysis of the driving force of the crack growth and crack growth rate of stress corrosion cracking (SCC), compact tensile specimen (1T-CT) is used, and the geometric dimension of the specimen is shown in Figure 1. The initial precrack length $a=2 \mathrm{~mm}$. During the SCC process, a dense oxide film is formed at the crack tip of $316 \mathrm{~L}$ SS. The thickness of the oxide film varies according to the corrosion environment. The thickness of the oxide film is generally $0.1 \mu \mathrm{m} \sim 2 \mu \mathrm{m}$ [8]. In the study, the geometric model of the oxide film at the crack tip of SCC is simplified as shown in Figure 1, and the thickness of the oxide film is $0.5 \mu \mathrm{m}$.

According to the location of the SCC crack in welded joints in nuclear power plants, SCC cracks are easily generated in the heat-affected zone and the fusion line, and cold working at heat effects can occur due to the welding process.

The distribution of cracks in different positions of welded joint is shown in Figure 1. When a crack initiates at the interface, the crack coincided with fusion line, and two sides of the crack are nickel-based 600 and 316L SS. When a crack initiates in the heat-affected zone, the distance $d$ between the crack and fusion line is $5 \mu \mathrm{m}$ and $15 \mu \mathrm{m}$, respectively.

3.2. Mechanical Model. The structure material for nuclear power pipelines is $316 \mathrm{~L} \mathrm{SS}$, and material for welds is nickelbased 600 . Both are power hardening materials. Therefore, the Ramberg-Osgood ( $\mathrm{R}-\mathrm{O})$ relationship is selected as the constitutive equation.

$$
\frac{\varepsilon}{\varepsilon_{y}}=\frac{\sigma}{\sigma_{y}}+\alpha\left(\frac{\sigma}{\sigma_{y}}\right)^{n}
$$

The heat-affected zone of the welded joint has a different level of cold working due to cold shrinkage of the weld. To simulate the different level of cold working in the heat-affected zone, tensile experiments were used to $316 \mathrm{~L}$ SS by $10 \%$ and $20 \%$, respectively, to obtain mechanical parameters of material with a different level of cold working. Young's modulus of the oxide film is about $70 \%$ of metal material's [9]. Therefore, Young's modulus of the oxide film at the crack tip is $140 \mathrm{GPa}$, and the Poisson ratio of the oxide film is 0.3. In experiment, stress intensity factor $K_{\mathrm{I}}=30 \mathrm{MPa} \cdot \mathrm{m}^{1 / 2}$ [10]. It is assumed that nickel-based 600 and 316L SS have the same creep parameters. The mechanical parameters of materials are shown in Table 1.

3.3. Finite Element Model. Using the numerical simulation method, the finite element model is as shown in Figure 2. The plane strain model is adopted in finite element analysis because the crack in the nuclear power pipeline conforms to the plane strain model. The crack tip adopts a circular arc shape. The submodel technology is used to refine the crack tip to obtain more accurate simulation data. Both the global 


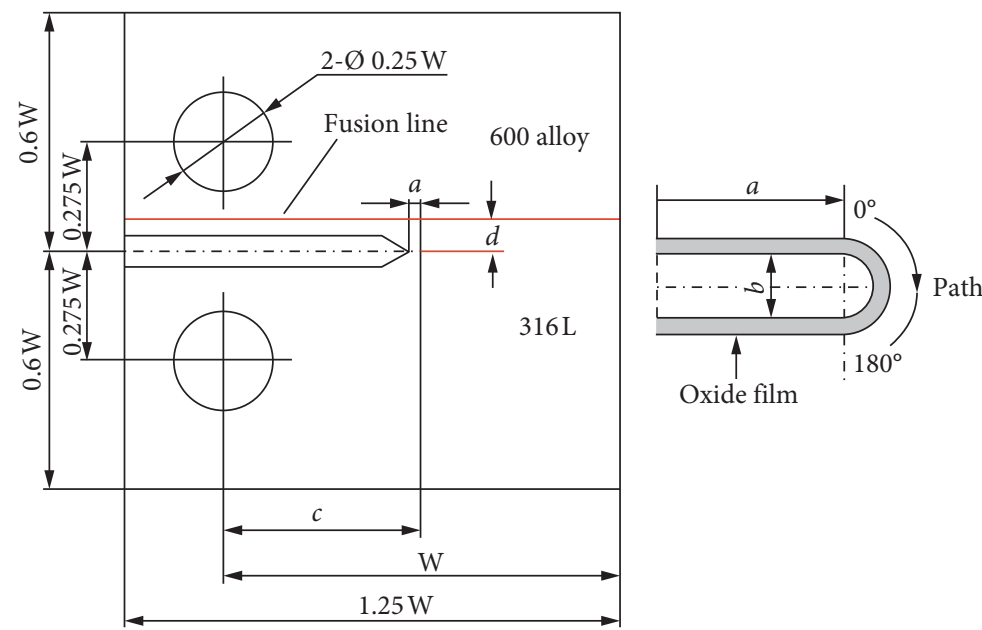

FIgURE 1: Sample geometry and schematic diagram at the crack tip ( $W=50 \mathrm{~mm}, c=0.5 \mathrm{~W}, a=2 \mathrm{~mm}$, and $b=1 \mu \mathrm{m})$.

TABLe 1: Mechanical parameters of materials.

\begin{tabular}{lccccc}
\hline Mechanical parameters & 600 alloy & 316L-CW0 & 316L-CW10 & 316L-CW20 & Oxide film \\
\hline Yield strength $(\mathrm{MPa})$ & $436[11]$ & 238 & 416 & 589 & - \\
Young's modulus $(\mathrm{GPa})$ & 189.5 & 195 & 193 & 189 & 0.3 \\
Poisson's ratio & 0.286 & 0.3 & 0.3 & 6.9 & 0.3 \\
Hardening exponent & 6.495 & 4.6 & 0.96 & 0.67 & - \\
Hardening coefficient & 3.075 & 1.68 & 9.7 & - \\
\hline
\end{tabular}

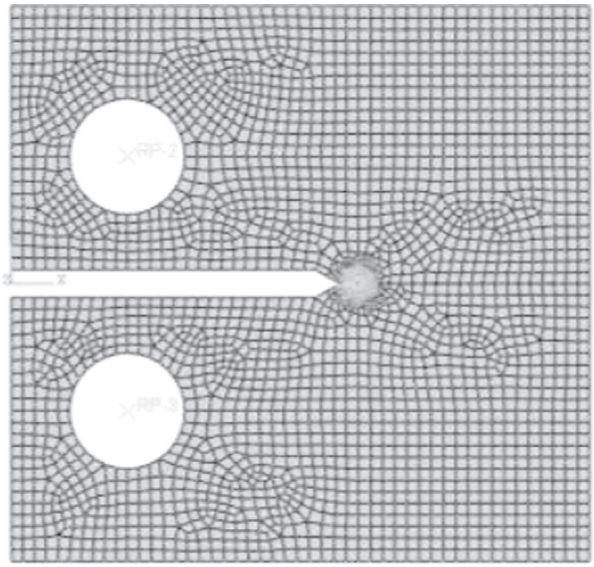

(a)

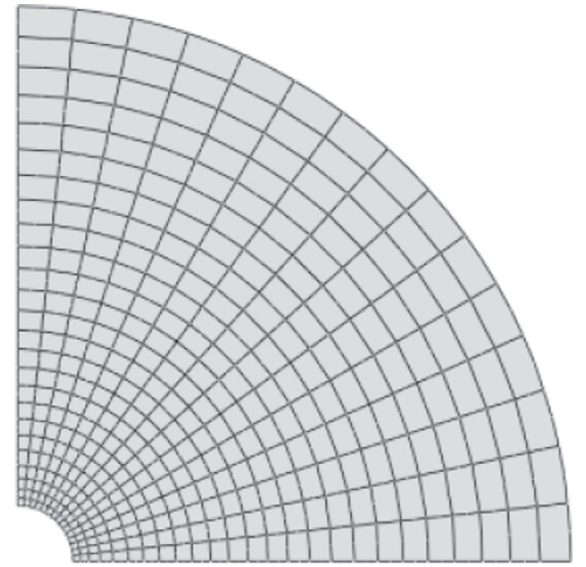

(b)

FIGURE 2: Finite element model.

model and submodel use an 8-node quadratic plane strain element (CPE8). The discrepancy of material properties in the finite element model is marked in Figure 1.

\section{Analysis of Tensile Stress at the Crack Tip}

One overload occurs in service, and the microregion at the crack tip will harden. The hardening of the microregion at the crack tip will affect the distribution of stress field at the crack tip. The tensile stress direction is consistent with the external load direction, and it is perpendicular to the crack opening direction, which can truly reflect stress at the crack tip. Therefore, distribution of tensile stress at the crack tip is mainly analyzed. When SCC crack is on the fusion line, tensile stress at the crack tip with and without hardening is as shown in Figure 3. It can be seen from the figure that tensile stress at the crack tip with hardening is greater. Because the material in the microregion at the crack tip is hardened and plasticity becomes worse, it is not easy to deform and release stress. The mechanical properties of the two sides of the crack are different, and the distribution of tensile stress is also asymmetric.

Cold working is generated due to cold shrinkage of the heat-affected zone. The effect of cold working of 316L SS in the heat-affected zone on tensile stress at the crack tip on the fusion line is shown in Figure 4 . It can be seen from the figure that the higher the cold working level of 316L SS in the 


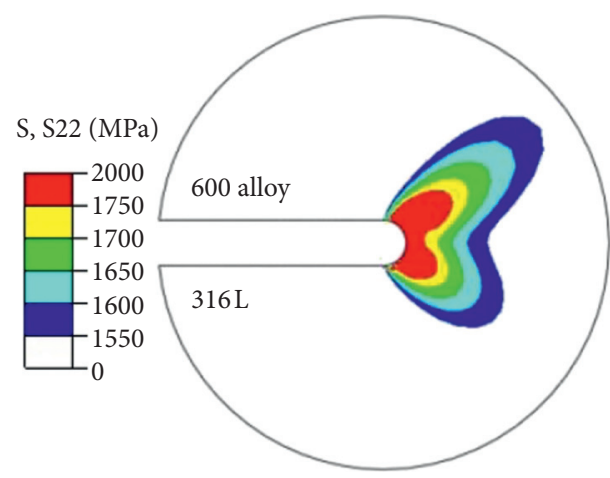

(a)

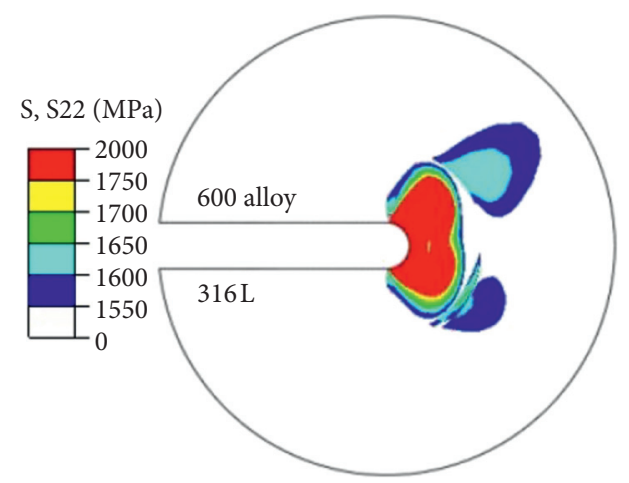

(b)

Figure 3: Comparison of tensile stress between the crack tip with and without hardening. (a) Without hardening. (b) With hardening.

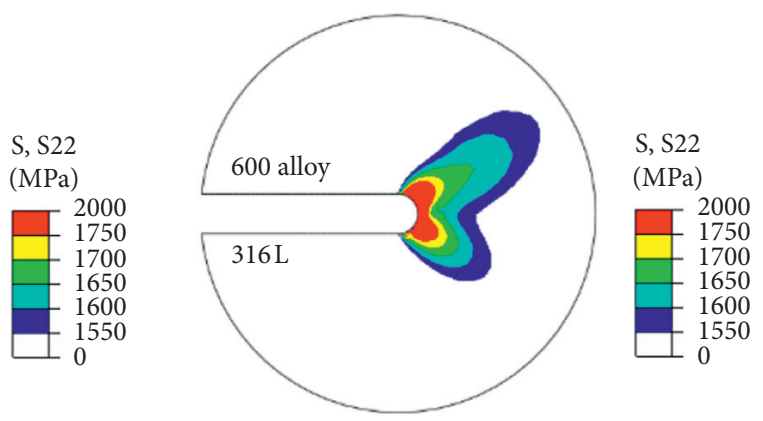

(a)

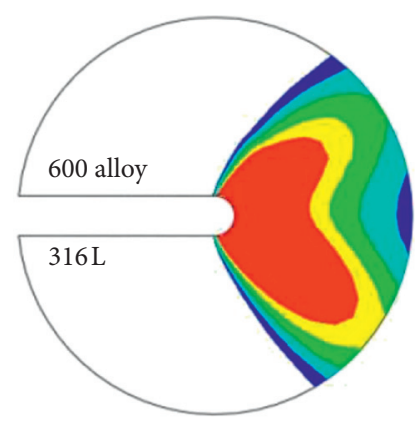

(b)

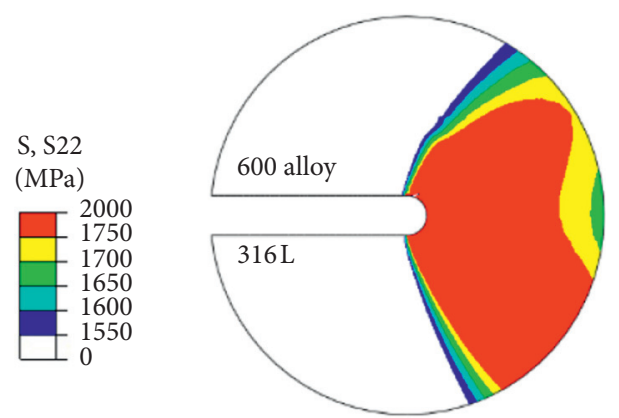

(c)

FIGURE 4: Effect of cold working on tensile stress. (a) CW 0. (b) CW 10. (c) CW 20.

heat-affected zone, the greater the tensile stress at the crack tip, and tensile stress is more and more biased to the 316L SS side as the cold working level of 316L SS increases. Tensile stress is more and more concentrated on the side with higher level of cold working because the metal with higher level of cold working is less plastic and less prone to deformation.

When the crack is in the heat-affected zone, the effect of cold working of material in the heat-affected zone on tensile stress is as shown in Figure 5. It can be seen that when $d=5 \mu \mathrm{m}$ and $d=15 \mu \mathrm{m}$, and there is no cold working in the heat-affected zone, the yield strength and hardening exponent of 600 alloy are higher than that of 316L SS, and so tensile stress shifts toward the 600 alloy. As the level of cold working in the heat-affected zone increases, the tensile stress at the crack tip shifts toward 316L SS. Because the level of cold working of 316L SS is higher than that of nickel-based alloys, it can be seen that tensile stress will shift to the side where the material is at high level of cold working. When the level of cold working is higher, tensile stress is also relatively greater. Comparing the distribution tensile stress at the crack tip with $d=5 \mu \mathrm{m}$ and $d=15 \mu \mathrm{m}$, it can be seen that when the crack tip is closer to the weld, the tensile stress at the crack tip is greatly affected by mechanical parameters of 600 alloy. As $d$ increases, the crack tip gradually moves away from weld, and tensile stress at the crack tip is greatly affected by the mechanical properties of 316L SS in the heat-affected zone.

\section{Effect of Cold Working on the Driving Force of Crack Growth}

5.1. Effect of Cold Working on the Driving Force of Crack Growth on the Fusion Line. On the one hand, hardening at the crack tip will improve mechanical properties of the crack 


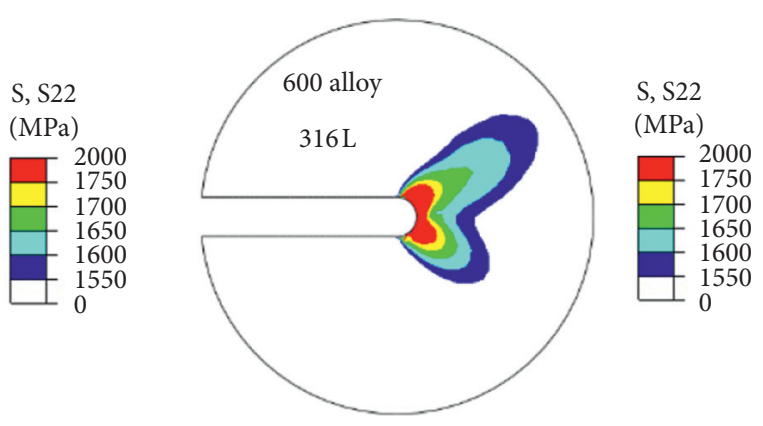

(a)

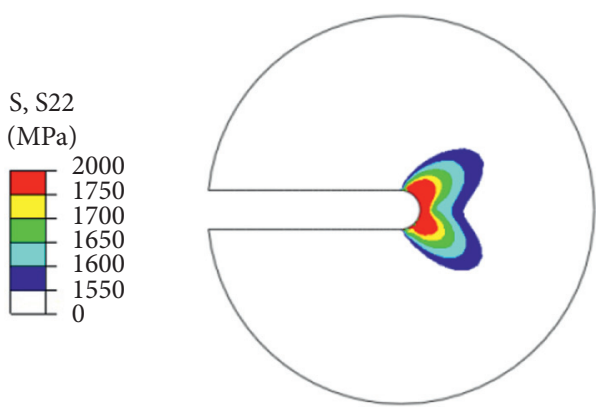

(c)

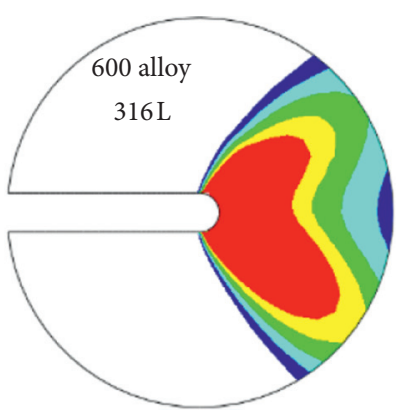

(b)

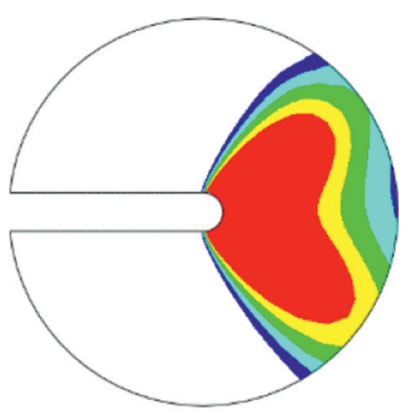

(d)

Figure 5: Effect of cold working on tensile stress at different distances from the fusion line. (a) $d=5 \mu \mathrm{m}, 316 \mathrm{~L}-\mathrm{CW}$. (b) $d=5 \mu \mathrm{m}$, $316 \mathrm{~L}-$ CW10. (c) $d=15 \mu \mathrm{m}, 316 \mathrm{~L}-\mathrm{CW} 0$. (d) $d=15 \mu \mathrm{m}, 316 \mathrm{~L}-\mathrm{CW} 10$.

tip. When external load is constant and the crack tip is hardened, the plasticity of the crack tip decreases and the stress of the crack tip increases. On the other hand, due to the restraint of the crack tip, hardening of the crack tip will generate residual compressive stress at the crack tip. Therefore, only considering hardening of the crack tip without considering the residual stress, when the crack tip is hardened, the tensile stress is greater. When the hardening at the crack tip and residual stress are considered at the same time, the effective stress at the crack tip should be the combination of tensile stress and residual stress. The effective stress is used in the calculation of the driving force and crack growth rate. When the crack occurs on the fusion line, the $0^{\circ}-90^{\circ}$ area of the crack tip belongs to the weld area, and the material is nickel-based 600 and the $90^{\circ}-180^{\circ}$ area belongs to the heat-affected area, and material is $316 \mathrm{~L} \mathrm{SS}$. To study the distribution of the creep rate at different distances from crack tips, three paths from the crack tip, $r=0 \mu \mathrm{m}$, $r=0.2 \mu \mathrm{m}$, and $r=0.4 \mu \mathrm{m}$, were chosen and analyzed.

When the crack tip is not hardened and the heat-affected zone is not cold-worked, the creep rate at the crack tip is as shown in Figure 6. It can be seen from the figure that the closer to the crack tip, the greater the creep rate of crack tip and the greater the driving force for crack growth. The value and distribution of the creep rate at the crack tip are affected by mechanical properties of the weld and heat-affected zone. The yield strength and hardening exponent of the nickelbased 600 in the weld zone are higher than those of 316L SS in the heat-affected zone, and the maximum value of the creep rate at the crack tip is biased toward the weld material.

When the crack tip is hardened and the heat-affected zone is not cold-worked, the distribution of the creep rate at the crack tip is as shown in Figure 7. It can be seen from the figure that the closer to the crack tip, the higher the creep rate. The maximum value of the creep rate at the crack tip did not appear at $90^{\circ}$ in front of the crack tip, but was biased towards the weld zone.

The distribution of the creep rate at the crack tip with and without hardening is shown in Figure 8. It can be seen that the creep rate at the crack tip with hardening is smaller. This is because although the hardening at the crack tip increases tensile stress, it also generates residual compressive stress. The residual compressive stress needs to be overcome when reloading, which will temporarily reduce the stress at the crack tip.

The effect of cold working on the creep rate at the crack tip is shown in Figure 9. It can be seen from the figure that the value of the maximum creep rate appears in weld when there is no cold working in the heat-affected zone. As the level of cold working in the heat-affected zone increases, the maximum value of the creep rate will shift. When the mechanical properties of material in the heat-affected zone are higher than those of the material in the weld zone, the maximum value of the creep rate appears in the heat-affected zone, and the maximum value of creep rate increases. As the level of cold working in the heat-affected zone further increases, the maximum value of the creep rate also increases rapidly, and the maximum value of the creep rate is still in the heat-affected zone. Therefore, the creep rate tends to be on the side of the material with higher level of cold working.

5.2. Effect of Cold Working on the Driving Force of Crack Growth in the Heat-Affected Zone. The creep rate at the crack tip of cold working 316L SS in the heat-affected zone is 


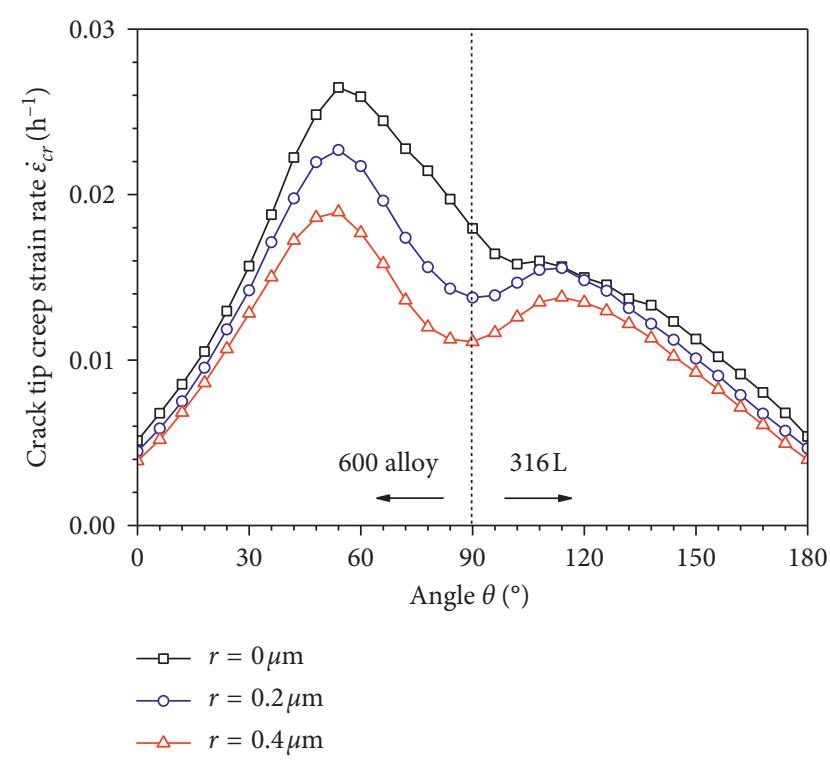

FIGURE 6: Creep rate of the crack tip without hardening.

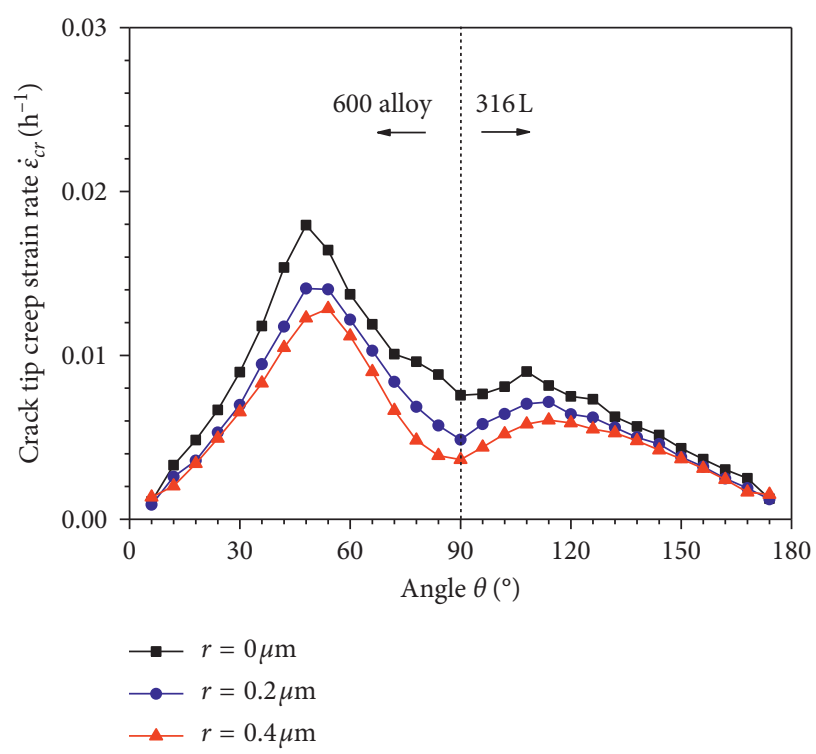

FIgURE 7: Creep rate of the crack tip with hardening.

shown in Figure 10 when the crack is in the heat-affected zone. It can be seen that the higher the level of cold working, the greater the creep rate and the greater the driving force for crack growth. The maximum value of the creep rate is gradually away from the weld zone, and the maximum value of the creep rate increases rapidly. That is, the higher the level of cold working, the greater the driving force for crack growth.

The distribution of the creep rate at the crack tip is shown in Figure 11 when the distance between the fusion line and crack tip is different. It can be seen from the figure that the crack is closer to the weld fusion line, the creep rate is greatly affected by the weld material, and the maximum value of the creep rate is also biased toward the weld zone. When the crack is far away from the weld, the creep rate is mainly affected by mechanical parameters of 316L SS in the

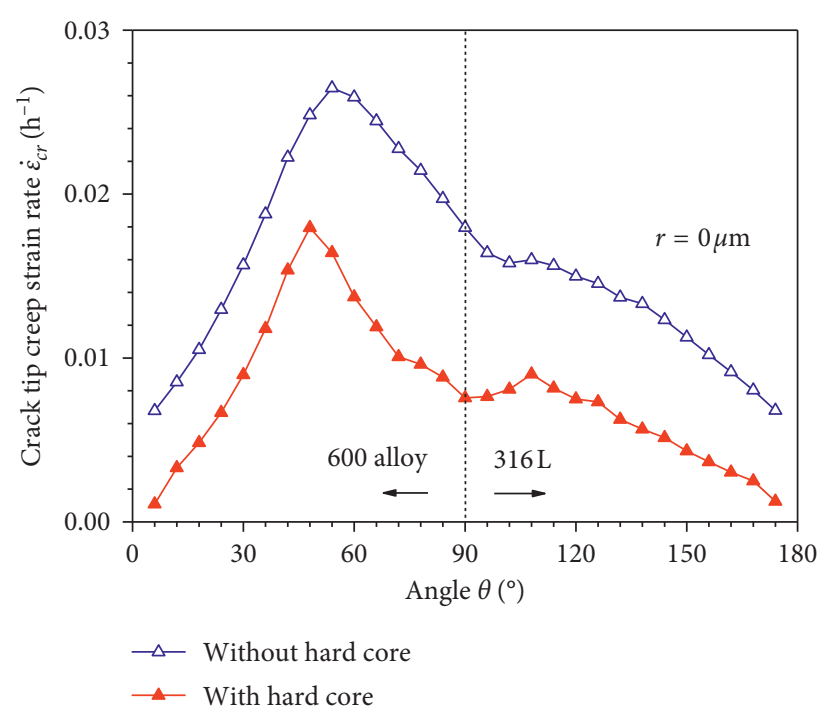

FIgURE 8: Comparison of the creep rate of the crack tip with and without hardening.

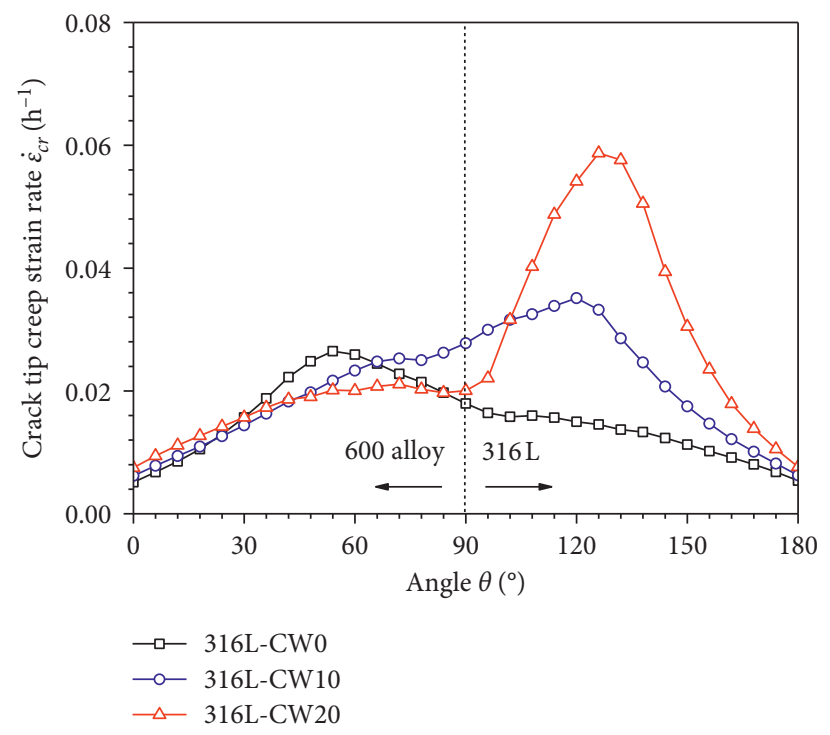

FIGURE 9: Effect of cold working of the heat-affected zone on the creep rate.

heat-affected zone, and the effect of mechanical properties in weld gradually decreases.

\section{Effect of Cold Working on the Crack Growth Rate}

The effect of cold working of 316L SS in the heat-affected zone on the crack growth rate is shown in Figure 12 when the crack is on the fusion line of the weld. It can be seen from the figure that with the higher level of cold working of $316 \mathrm{~L}$ SS in the heat-affected zone, the maximum value of the crack growth rate is gradually transferred from the weld to the heat-affected zone. The maximum value of the crack growth rate is biased toward the side of metal with higher levels of cold working. The higher level of cold working in 


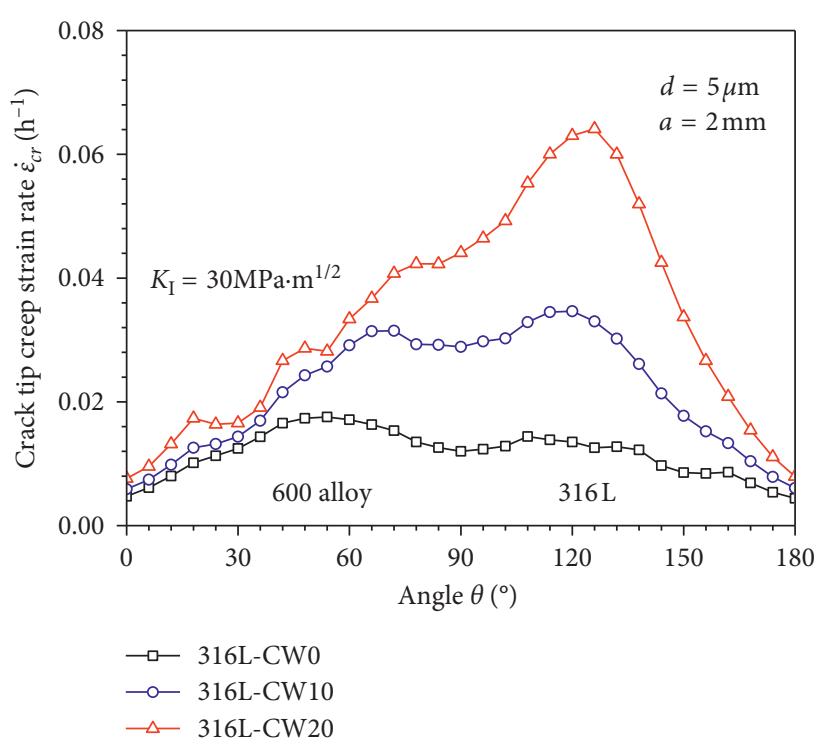

FIGURE 10: Effect of cold working on the creep rate.

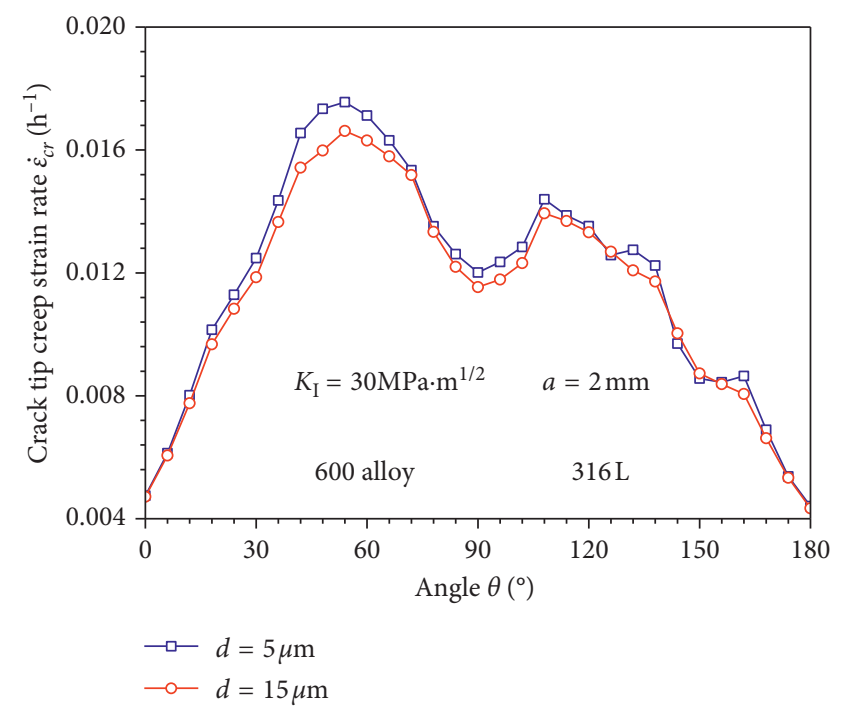

Figure 11: Effect of distance of the crack from the fusion line on the creep rate.

the heat-affected zone, the greater the crack growth rate, and the crack growth rate increases rapidly with the increase of the level of cold working. The cold working of material increases the crack growth rate of SCC, which is an unfavorable factor.

Figure 13 shows the comparison of the crack growth rate at the crack tip with hardening and without hardening when the crack is on the fusion line. It can be seen from the figure that the crack growth rate is smaller when the crack tip is hardened, and the hardening at the crack tip has a greater effect on the crack growth rate. The crack tip with hardening reduces the crack growth rate within a certain range, which may be a favorable factor.

When crack appears in the heat-affected zone at a distance $d=5 \mu \mathrm{m}$ from the fusion line, the effect of cold working in the heat-affected zone on the crack growth rate is

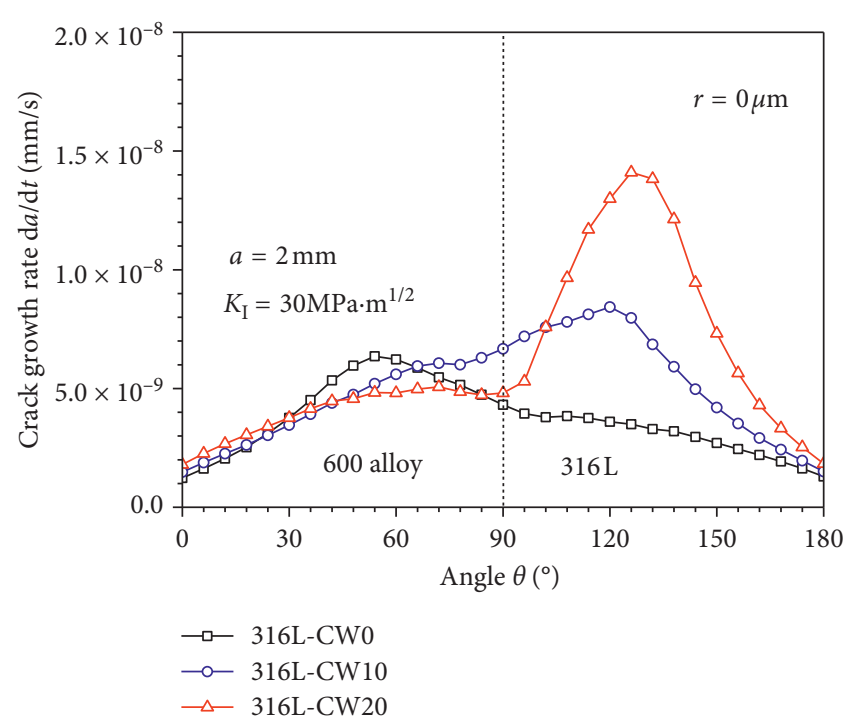

FIGURE 12: Effect of cold working on the crack growth rate on the fusion line.

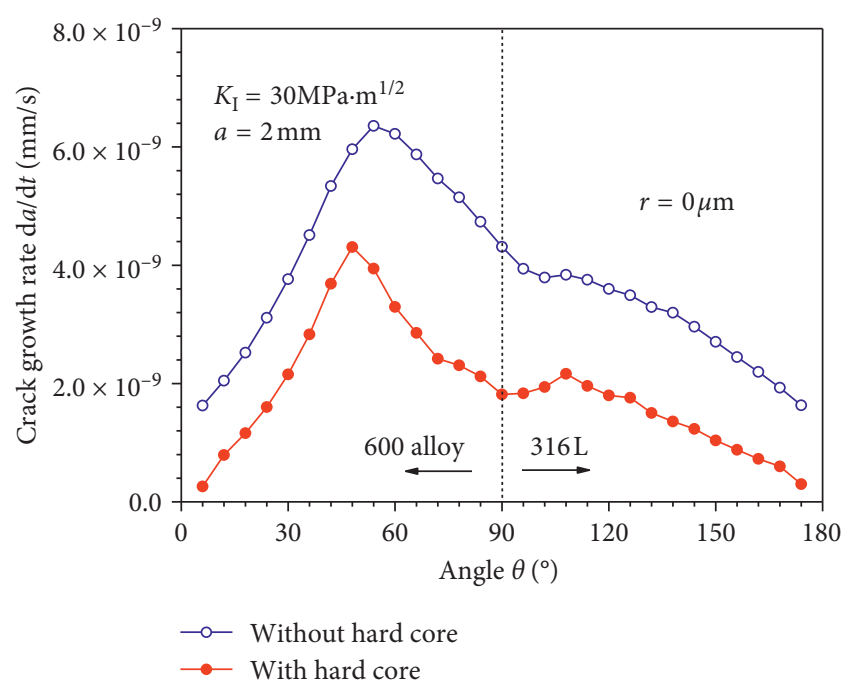

FIGURE 13: Comparison of the crack growth rate between the crack tip with and without hardening.

as shown in Figure 14. It can be seen that as the level of cold working of $316 \mathrm{~L}$ SS in heat-affected zone increases, the maximum value of the crack growth rate gradually moves away from the weld zone. The higher the level of cold working of $316 \mathrm{~L} \mathrm{SS}$, the greater the crack growth rate. It can be seen that cold working of material increases the crack growth rate.

Figure 15 compares the crack growth rate in the heataffected zone when the distance between the crack and fusion line is different. It can be seen from the figure that the greater the distance between the crack tip and fusion line, the greater the crack growth rate. This is because mechanical properties of the metal in the heat-affected zone are higher than those of the weld metal. At this time, the crack growth rate is greatly affected by the mechanical properties of the metal in the heat-affected zone. 


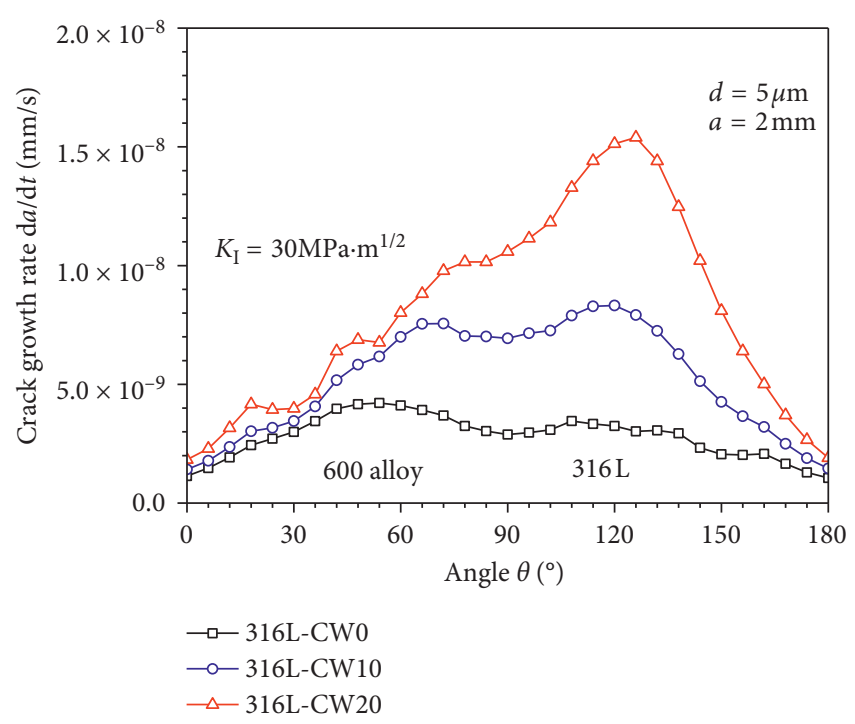

FIGURE 14: Effect of cold working on the crack growth rate of the heat-affected zone.

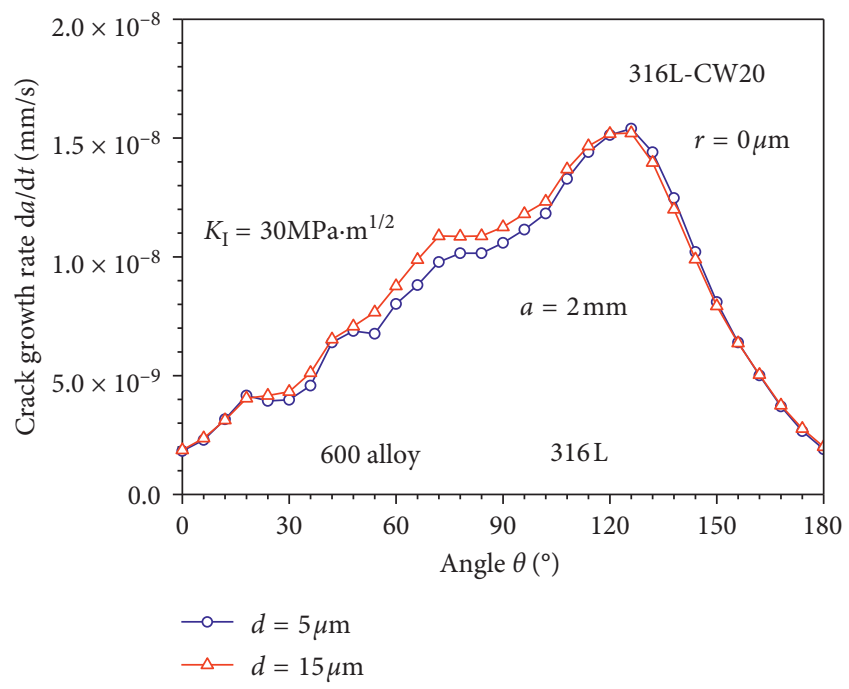

FIGURE 15: Comparison of the crack growth rate at different distances from the fusion line.

\section{Conclusions}

(1) Using the creep rate of the crack tip to replace the strain rate of the crack tip in the Ford-Andresen model, the driving force of the crack growth and crack growth rate calculation models are optimized, which is more convenient for practical application.

(2) The mechanical properties of the metal on both sides of the fusion line are different, and the tensile stress is different. The tensile stress will be biased toward the side of metal with a higher level of cold working. As the level of cold working in the heat-affected zone increases, tensile stress is obviously biased towards the heat-affected zone, and the tensile stress increases as the level of cold working increases.
(3) Both the driving force of the crack growth and crack growth rate increase with the level of cold working of material in the heat-affected zone, and the maximum value of the crack growth driving force and crack growth rate are biased toward the side of the metal with a high level of cold working. The farther the crack tip is from the fusion line, the smaller the effect of the crack growth driving force and crack growth rate on mechanical properties of weld metal, and the greater the effect on mechanical properties of metal in the heat-affected zone.

(4) One overload will cause the crack tip of SCC to harden. The hardening of the crack tip not only increases the tensile stress to a certain extent but also generates residual compressive stress. Therefore, the driving force of the crack growth and crack growth rate is reduced to a certain extent.

\section{Data Availability}

1. Previously reported Young's modulus and Poisson's ratio of the oxide film were used to support this study and are available at https://doi.org/10.1016/S00406090(01)01464-X. These prior studies (and datasets) are cited at relevant places within the text as references [9]. 2. Mechanical parameters of nickel-based alloy 600 were used to support this study and are available at https://doi.org/10.1016/j.ijpvp.2019.04.005. These prior studies (and datasets) are cited at relevant places within the text as references [11]. 3. The data of mechanical parameters of 316L SS with a different level of cold working are obtained by the research group through the tensile test. 4 . The numerical simulation data at the crack tip of $316 \mathrm{~L}$ stainless steel used to support the findings of this study are included in the article.

\section{Conflicts of Interest}

The authors declare that they have no conflicts of interest.

\section{Acknowledgments}

This work was financially supported by the International Exchanges Programme Scheme project by the National Natural Science Foundation of China and the Royal Society (51811530311) and National Natural Science Foundation of China (51475362).

\section{References}

[1] K. Chen, D. Du, W. Gao et al., "Effect of cold work on the stress corrosion cracking behavior of Alloy 690 in supercritical water environment," Journal of Nuclear Materials, vol. 498, pp. 117-128, 2018.

[2] J. Chen, Z. Lu, Q. Xiao et al., "The effects of cold rolling orientation and water chemistry on stress corrosion cracking behavior of $316 \mathrm{~L}$ stainless steel in simulated PWR water environments," Journal of Nuclear Materials, vol. 472, pp. 112, 2016.

[3] G. J. Li, Research on Performance of Dissimilar Metal Welded Parts SA508-52M-316L in Simulated PWR Primary Water 
Environment, Shanghai Institute of Materials, Shanghai, China, 2011.

[4] H. Xue, Z. Li, Z. Lu, and T. Shoji, "The effect of a single tensile overload on stress corrosion cracking growth of stainless steel in a light water reactor environment," Nuclear Engineering and Design, vol. 241, no. 3, pp. 731-738, 2011.

[5] C. Bichler and R. Pippan, "Effect of single overloads in ductile metals: a reconsideration," Engineering Fracture Mechanics, vol. 74, no. 8, pp. 1344-1359, 2007.

[6] P. L. Andresen and F. Peter Ford, "Life prediction by mechanistic modeling and system monitoring of environmental cracking of iron and nickel alloys in aqueous systems," Materials Science and Engineering: $A$, vol. 103, no. 1, pp. 167-184, 1988.

[7] Q. J. Peng, J. Kwon, and T. Shoji, "Development of a fundamental crack tip strain rate equation and its application to quantitative prediction of stress corrosion cracking of stainless steels in high temperature oxygenated water," Journal of Nuclear Materials, vol. 324, no. 1, pp. 52-61, 2004.

[8] Z. Wang and Y. Takeda, "Amorphization and structural modification of the oxide film of Ni-based alloy by in-situ $\mathrm{H}$ charging in high temperature high pressure water environment," Corrosion Science, vol. 166, 2020.

[9] P. Goudeau, P. O. Renault, P. Villain et al., "Characterization of thin film elastic properties using $\mathrm{X}$-ray diffraction and mechanical methods: application to polycrystalline stainless steel," Thin Solid Films, vol. 398-399, pp. 496-500, 2001.

[10] K. Chen, J. Wang, D. Du, P. L. Andresen, and L. Zhang, "dK/ $\mathrm{d} a$ effects on the SCC growth rates of nickel base alloys in high-temperature water," Journal of Nuclear Materials, vol. 503, pp. 13-21, 2018.

[11] K. Zhao, H. Xue, F. Yang, and L. Zhao, "Probability prediction of crack growth rate of environmentally assisted cracks of nickel-based alloys based on Latin hypercube sampling," International Journal of Pressure Vessels and Piping, vol. 172, pp. 391-396, 2019. 